\title{
Accurate automated quantitative imaging of tortoise erythrocytes using the NIS image analysis system
}

\author{
S. Walton, M.D. Hofmeyr and G. van der Horst
}

\begin{abstract}
The standard method for assessing blood cell characteristics using an ocular micrometer is time-consuming and limited. We used the Nikon NIS Elements imaging software and May-Grünwald-Giemsa staining to determine whether automated image analysis is suitable for rapid and accurate quantitative morphometry of erythrocytes. Blood was collected during four seasons from 126 geometric tortoises and the blood smears were evaluated for cell (C) and nuclear (N) characteristics of the erythrocytes. We measured area, length (L), width (W), perimeter, elongation and pixelation intensity, and calculated L/W and N/C areas. Erythrocyte size differed among cohorts; females, the larger sex, had smaller erythrocytes than either males or juveniles. Males had more elongated erythrocytes than females and erythrocytes of adults were more elongated than those of juveniles. Erythrocyte size and shape influence the efficiency of gas exchange owing to surface area to volume ratios, which are greater for small, elongated cells than for large, round cells. The high $\mathrm{N} / \mathrm{C}$ ratio and low pixelation intensities of males and juveniles indicate that they may have had more immature erythrocytes in their circulation than females. The use of pixelation intensity to indicate the presence of immature erythrocytes was validated by seasonal differences that corresponded to the biology of the tortoises. Pixelation intensity was lowest in winter. We found that automated image analysis is a rapid and reliable method for determining cell size and shape, and it offers the potential for distinguishing among developmental stages that differ in staining intensity. The method should be useful for rapid health assessments, particularly of threatened species, and for comparative studies among different vertebrates.
\end{abstract}

A thorough hematological evaluation includes red and white blood cell counts and assessment of morphology (Campbell 2004). Collecting blood for blood smears is minimally invasive, easily performed in wild populations, and has been used with success to assess an animal's health and physiological state (Arikan and Cicek 2010). Knowledge of vertebrate blood cell morphology and function is based mainly on mammals (Claver and Quaglia 2009); there are few studies of lower vertebrates, particularly rep- tiles (Campbell 2004, Strik et al. 2007). Leukocyte types correspond broadly among all vertebrate groups, but non-mammalian vertebrates have nucleated thrombocytes and erythrocytes in contrast to the anucleated blood platelets and red blood cells of mammals (Campbell 2004, Claver 
and Quaglia 2009). Despite these differences in blood cell morphology, polychromatic Romanowsky stains have been used successfully for all vertebrate groups to identify blood cell types and lineages, and to differentiate cytoplasmic and nuclear components (Pendl 2006).

The most abundant circulating blood cells are erythrocytes, which are responsible for oxygen transport throughout the body (Morera and MacKenzie 2011). The size of erythrocytes varies thirty-fold among vertebrate groups; birds and mammals have smaller erythrocytes than fish, amphibia and reptiles (Snyder and Sheafor 1999). Erythrocyte size has been linked to oxy- gen transport capacity; the efficiency of respiratory gas exchange is greater in small cells with large surface area to volume ratios (Gregory et al. 2009). Animals with high metabolic demands, such as endothermic birds and mammals, have small cells ostensibly to provide the required level of gas exchange for metabolism (Gregory 2001, Andrews et al. 2008, Gregory et al. 2009). Spherical cells have the smallest surface area to volume ratio of all cell shapes; consequently, elliptical cells exchange gases more efficiently than round cells (Hartman and Lessler 1964, Shadkhast et al. 2010). Erythrocyte shapes among vertebrate groups range from highly elongated in lizards to oval in chelonians and nearly spherical in some teleost fish (Hartman and Lessler 1964, Saint Girons 1970). Erythrocyte morphology also may differ among cohorts, e.g., juvenile reptiles often have rounder erythrocytes than adults (Mader 2000, Campbell 2004) and males may have larger erythrocytes than females (Ponsen et al. 2008).

The lifespan of red blood cells is finite and immature replacement erythrocytes often are detected in bloodsmears of non-mammalianvertebrates(Camp- bell 2004, Morera and MacKenzie 2011). Immature and mature erythrocytes differ in shape (round vs. oval), staining characteristics (deeply basophilic vs. neutral to acidophilic) and the size of the nucleus is decreased, relative to cell size, with maturity (Reavill 1994, Mader 2000, Zhang et al. 2011). An increase in the abundance of immature erythrocytes indicates increased erythropoeiesis, which may occur in response to environmental change, e.g., temperature, (Dessauer 1970, Reavill 1994), physiological state, e.g., ecdysis, (Campbell 2004) or disease (Reavill 1994, Mader 2000, Campbell 2004). Disease conditions associated with an increased level of immature cells in the circulation include viral and bacterial infections, parasite infestation, exposure to toxins, and nutritional deficiencies (Aird 2000, Strik et al. 2007).

Clearly, quantification of the morphological characteristics of erythrocytes would contribute to understanding and comparing species, sex and seasonal differences, and to assessing the health status of non-mammalian vertebrates. Two of the major obstacles, however, are the time required to measure the various morphometric details of erythrocytes and the need to quantify these measurements objectively and accurately. The standard technique for making these measurements involves the use of an ocular calibrated in micrometers, with measurements limited to length (L) and width (W), from which erythrocyte and nuclear sizes were calculated according to the modified area 
equation for an eclipse: $L W \pi / 4$ (Arikan and Cicek 2010). Because this method is timeconsuming and includes a source of subjective bias, a rapid, accurate and preferably automated imaging system would be more appropriate.

We used the Nikon NIS Elements imaging software to evaluate erythrocyte morphology of geometric tortoises, a critically endangered species endemic to the southwestern Cape, South Africa (Baard and Hofmeyr, in press). Our study is part of a wider initiative to establish baseline hematological parameters for all South African chelonians. We combined a suitable staining technique with sophisticated image analysis to quantify the morphological characteristics of chelonian erythrocytes accurately and objectively. We expect that this technique may become an important tool for making rapid health assessments on wild populations and for comparing erythrocytes of fish, amphibians, reptiles and birds, whose erythrocytes share many similarities.

\section{Materials and methods Sample collection}

Our investigation was carried out under CapeNa- ture permit number AAA004-00019o035 and UWC project registration number with ethics clearance 96/10/15. Blood samples were obtained during four seasons at Elandsberg Nature Reserve (380o ha, $33^{\circ} 26$ 'S; $19^{\circ} \mathrm{O}$ ' E) in the southwestern Cape, South Africa, from 126 healthy, free-ranging male, female and juvenile geometric tortoises, Psammobates geometricus. To limit stressinduced changes to blood composition, blood was sampled from unanesthetized tortoises immediately after capture. The mass of each animal determined the maximum blood volume sampled; care was taken not to exceed $0.5 \%$ of an animal's field body mass, a conservative veteri- nary standard (Mader 2000). A 25 gauge needle with a 1 or $2 \mathrm{ml}$ syringe was used to collect blood from either the jugular vein (Mader 2000) or carotid artery. Because EDTA is known to cause lysis of chelonian cells (Harding et al. 2005, Knotek et al 2006), heparin was used as an anticoagulant, although it has been observed to impart a blue tinge to blood smears and to cause clumping of cells (Houwen 2000). Sampling normally took 1-2 min and if an adequate sample was not obtained in approximately $5 \mathrm{~min}$, sampling was stopped to avoid stress to the animal. The animals were kept under observation for $24 \mathrm{~h}$ and during the dry season access to drinking water was provided before returning the animals to the capture site.

\section{Histological preparation}

Duplicate blood smears were prepared using the wedge-smear technique with a single-use, bevel- edged glass slide spreader (Pendl 2006). Smears were air dried, fixed in absolute methanol and stored in dust-free boxes until staining. Best staining results were obtained using the May-Grünwald-Giemsa stains as described by Houwen (2000). May- Grünwald reagent powder was supplied by Saarchem (Pty.) Ltd, and all other chemical reagents were supplied by Merck manufacturers (Cape Town, South Africa). To prepare the stock solutions, 0.3 g, May-Grünwald's eosin-methylene blue (C.I. 45380/52015) was added to $100 \mathrm{ml}$ absolute methanol, left to stand overnight, then filtered. One gram of Giemsa's azure-eosin-methylene blue (C.I. 52010/45380/52015) was added to $66 \mathrm{ml}$ glycerol, 
heated to $56^{\circ} \mathrm{C}$ for $100 \mathrm{~min}$, then mixed with $66 \mathrm{ml}$ absolute methanol and left to stand overnight. The solution was filtered and stored in an air-tight container. A pH 6.8 buffer $\left(\mathrm{Na}_{2} \mathrm{HPO}_{4} \cdot 2 \mathrm{H}_{2} \mathrm{O}, 0.47 \mathrm{~g} / \mathrm{l}\right.$ and $\left.\mathrm{KH}_{2} \mathrm{PO}_{4}, 0.47 \mathrm{~g} / \mathrm{l}\right)$ obtained from Merck was used to dilute stock solutions before staining. May-Grünwald stock was mixed with equal parts of buffer, whereas one part Giemsa stock was diluted with nine parts buffer. The May-Grünwald stain was applied to the blood smear for $5 \mathrm{~min}$, after which the excess solution was drained from the slide. Giemsa stain then was applied for $12 \mathrm{~min}$. The slide was rinsed once with buffer solution, washed with distilled water, and left to stand in distilled water for $3 \mathrm{~min}$. Stained blood smears were allowed to dry and later covered with a glass coverslip using Entellan new rapid mounting medium.

\section{Image analysis}

A Leica ICC50 camera in conjunction with a Leica DM 500 digital photomicroscope (40 X objective and total magnification of $400 \mathrm{X}$ ) was used to photograph blood cells in digital format for morphometric measurements using the Leica LAS soft- ware (v.1.8.o; Leica Microsystems Ltd., Heerbrugg, Switzerland). The images were saved as jpeg files (2048 X 1536 pixels), then analyzed using the Nikon NIS Elements (Basic Research version 3.10 Inc., Nikon Instruments Europe B.V., AS Amstelveen, The Netherlands) imaging software. Ten images were captured from the monolayer section of each blood smear. Each image contained at least 10 erythrocytes for which cellular boundaries did not overlap. For each erythrocyte, the following characteristics of both cell and nucleus were measured automatically: area (surface area of the image in $\mu \mathrm{m}^{2}$ ), length (the longest axis in $\mu \mathrm{m}$ ), width (calculated from area/length in $\mu \mathrm{m}$ ), perimeter (the total boundary calculated from four projections in the directions $0,45,90$ and 135 degrees using Crofton's formula (Solomon, 1978) (perimeter $\left.=\pi *\left(\operatorname{Pr}_{\mathrm{O}}+\operatorname{Pr}_{45}+\operatorname{Pr}_{90}+\operatorname{Pr}_{135}\right) / 4\right)$ in $\mu \mathrm{m}$ ), elongation (determined from Feret's diameters as MaxFeret/MinFeret; MaxFeret and MinFeret, respectively, which are the maximum and minimum diameters of an object measured every 10 degrees between $\mathrm{O}$ and 180 degrees) and pixelation (the statistical mean of intensities of pixels). The definitions above are according to the glossary of Nikon NIS Elements.

Images were measured after the micrometer scale was calibrated to pixel size using the program's calibration function ( 1 pixel $=0.16 \mu \mathrm{m}$ at $400 \mathrm{X}$ magnification). Background staining artefacts were eliminated by adjusting the contrast between nuclear and cellular staining, and by optimizing both brightness and contrast (both high and low ranges were set to their lowest value). In addition, white saturation intensity was adjusted to ensure optimal contrast of the image with the background. The auto detect thresholding function in the NIS- elements binary toolbar was used to select the best hue for relevant pixels to resolve cellular or nuclear boundaries of erythrocytes. The "erode or open" functions from the binary toolbar were used to match the cellular and nuclear boundaries precisely with the thresholded areas. NIS Elements then digitally automated erythrocyte measurements of cells and nuclei to a precision of $0.01 \mu \mathrm{m}$. Morphometric

\section{http://repository.uwc.ac.za}


measurements then were exported to a Windows Excel (MS Office) spreadsheet for analysis.

\section{Data and statistical analysis}

We used erythrocyte measurements to obtain two derived values for further analysis: the ratio of nuclear to cellular areas (N/C) for each erythrocyte and the width to length ratios $(\mathrm{W} / \mathrm{L})$ of each cell and its nucleus. Because our main objective was to demonstrate the efficacy of the Nikon NIS Elements imaging software for evaluating erythrocyte morphology, we did not perform a full analysis, but instead tested only whether cohort differences could be detected using the full data set (seasons combined) and whether seasonal differences could be detected (cohorts combined) for a selected characteristic, i.e., pixelation.

The data were not parametric. Consequently, we used Kruskal-Wallis ANOVAs on rank, followed by Dunn's post hoc comparisons to identify differences among cohorts and differences among seasons. Bonferroni corrections were applied to each family of tests to prevent Type I errors. We used SigmaStat (SPSS Inc., Chicago, IL, version 2.03) to evaluate the data statistically and we considered values for $p<0.05$ significant. We present summary statistics both as means and medians to allow comparison with the literature. Erythrocyte measurements usually are presented as means in the literature, even though the data may not be parametric.

\section{Results}

Mature erythrocytes were the most common component in peripheral blood of $P$. geometricus. The cells were oval to elliptical with a centrally placed round to oval, dark blue-purple staining nucleus, sometimes with an irregular border. The chromatin was visible as a coarse, evenly dispersed, strongly basophilic network. The abundant cytoplasm stained pale blue and was homogenous (Fig. 1A). The differentiation of nuclear and cellular boundaries often was obscured owing to the sampling procedure, staining artefacts or cellular debris. To overcome this, intensity and contrast were optimized (Fig. 1B), which revealed clear cellular and nuclear areas as well as reduced background staining and noise.

The auto-detect function for thresholding cellular and nuclear areas produced simultaneous, precise, automated thresholding of the erythrocyte or nuclear areas. To obtain an average of 100 cells per tortoise, 10 non-overlapping cells with uninterrupted cellular boundaries were selected randomly in 10 fields of view. For demonstrative purposes, 16 thresholded erythrocytes are shown in Fig. $1 \mathrm{C}$ and their nuclei in Fig. 1D. A strength of the technique is the automated measurements of the cells and their corresponding nuclei for the selected characteristics, six in this instance. Once the correct threshold settings were obtained as indicated in Fig. 1B-D, the process for cell and nuclear measurements per field could be performed within seconds. 

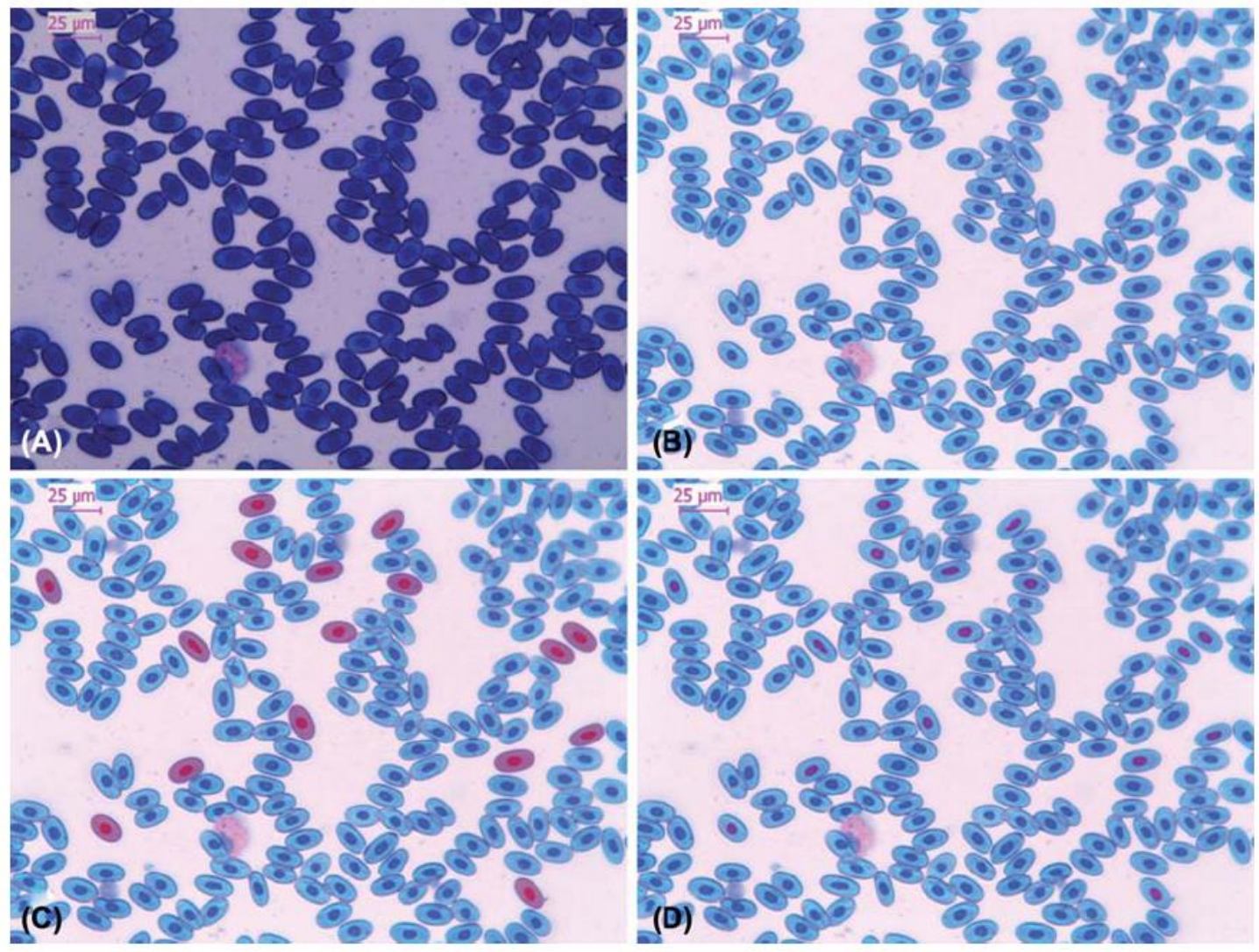

Fig. 1. A) Mature erythrocytes of Psammobates geometricus, showing basophilic nuclei and cytoplasm. Romanowsky staining. B) Brightness and contrast were optimized to eliminate background staining and to differentiate cellular and nuclear boundaries clearly. C) Using the auto-detect thresholding function, 16 randomly selected erythrocytes with uninterrupted cellular boundaries were highlighted for morphometric measurements. D) Subsequent thresholding shows the corresponding erythrocyte nuclei.

Geometric tortoise erythrocytes varied widely in size, with areas ranging between 53 and $275 \mu \mathrm{m}^{2}$ for the cells and 4 to $50 \mu \mathrm{m}^{2}$ for the nuclei (Table 1). Male and juvenile tortoises had larger cell and nuclear areas than females $\left(\mathrm{H}_{2}>99, p<0.0001\right)$. Cell length for males exceeded that of females and juveniles, whereas erythrocytes of juveniles were wider than either males or females $\left(\mathrm{H}_{2}>72, p<0.0001\right)$. Male and juvenile nuclei were longer than female nuclei and nuclear width was greatest for males and least for females $\left(\mathrm{H}_{2}>138, p\right.$ $<$ o.0001). The cell perimeter was longer in males than in females and juveniles, whereas the nuclear perimeter in males and juveniles was greater than that of females $\left(\mathrm{H}_{2}>110\right.$, $p<0.0001)$.

Cell shape varied from nearly $\operatorname{circular}(\mathrm{W} / \mathrm{L}=0.99$; elongation $=1.06)$ to highly elongated $(\mathrm{W} / \mathrm{L}=0.14$, elongation $=2.87)($ Table 1$)$. The $\mathrm{W} / \mathrm{L}$ ratio and elongation index (Fig. 2) differed among cohorts; male erythrocytes were the most elongated and juvenile erythrocytes were least elongated or most circular $\left(\mathrm{H}_{2}>238, p<0.0001\right)$. Results for nuclear shape were similar for $\mathrm{W} / \mathrm{L}$ and elongation indices; juveniles had the most elongated and females the least elongated nuclei $\left(\mathrm{H}_{2}>80, p<0.0001\right)$. The size of erythrocyte nucleus relative to cell size varied substantially $(3-32 \%)$ (Table 1 ), although care was taken not to 
select erythrocytes that were clearly immature. Both males and juveniles had larger nuclear to cellular ratios than females $\left(\mathrm{H}_{2}=164, p<0.0001\right)$.

Pixelation of cell cytoplasm and nucleoplasm reflected wide variation in intensity (Table 1). Cellular pixelation intensity was greater in females than in males or juveniles, which did not differ, whereas nuclear pixelation was also greatest in females. The intensity was greater for juveniles, however, than for males $\left(\mathrm{H}_{2}=116, p<0.0001\right)$. The pixelation index for erythrocyte cytoplasm was greater in the spring than during other seasons, although values for both summer and autumn were greater than during the winter (Fig. 3). Pixelation intensity of the nuclei also was greater in the spring, but pixelation during the summer was greater than in autumn and both seasons showed higher values than during winter $\left(\mathrm{H}_{3}>\right.$ 1139, $p<0.0001$ ) (Fig. 3).

\section{Discussion}

Morphological evaluation of erythrocytes provides valuable information concerning the physiological and health status of animals (Campbell 2004, Arikan and Cicek 2010). In addition to numbers of circulating cells, the size, shape and staining characteristics of red blood cells are important to hematologists (Arikan and Cicek 2010). Determining erythrocyte size and shape dimensions is critical, because the surface area to volume ratio of the hemoglobin-rich cells determines the efficiency of gas exchange, which ultimately enables metabolic function (Hartman and Lessler 1964). The effective use of polychromatic stains that combine basic and acidic dyes is important for accurate morphological analysis of erythrocytes.

Optimal staining of nucleated chelonian erythrocytes was obtained using the MayGrünwald-Giemsa stains as described by Houwen (2000) to differentiate both cytoplasmic and nuclear elements. 
Table 1. Summary statistics for erythrocyte cell and nuclear measurements of 126 geometric tortoises

\begin{tabular}{lcccrrrr}
\hline & Mean & \pm SD & Median & $\mathbf{2 5}^{\text {th }}$ & $\mathbf{7 5}^{\text {th }}$ & Min & Max \\
\hline Cell & & & & & & & \\
$\quad$ Area $\left(\mu \mathrm{m}^{2}\right)$ & 152.5 & 23.6 & 150.5 & 136.35 & 167.21 & 52.9 & 274.5 \\
Length $(\mu \mathrm{m})$ & 18.03 & 1.83 & 18.03 & 16.94 & 19.18 & 9.92 & 33.44 \\
Width $(\mu \mathrm{m})$ & 8.46 & 1.00 & 8.35 & 7.77 & 9.04 & 4.12 & 14.17 \\
W/L & 0.48 & 0.08 & 0.45 & 0.42 & 0.50 & 0.14 & 0.99 \\
Perimeter $(\mu \mathrm{m})$ & 46.68 & 3.73 & 46.45 & 44.10 & 48.94 & 27.39 & 76.02 \\
Elongation & 1.74 & 0.25 & 1.75 & 1.59 & 1.89 & 1.06 & 2.87 \\
Pixelation & 185.2 & 16.1 & 186.1 & 174.91 & 196.44 & 74.4 & 232.4 \\
Nucleus & & & & & & & \\
$\quad$ Area $\left(\mu \mathrm{m}^{2}\right)$ & 20.18 & 6.25 & 19.46 & 15.59 & 24.11 & 4.10 & 49.51 \\
Length $(\mu \mathrm{m})$ & 6.11 & 0.96 & 6.10 & 5.46 & 6.75 & 2.72 & 12.58 \\
Width $(\mu \mathrm{m})$ & 3.24 & 0.61 & 3.21 & 2.82 & 3.63 & 1.42 & 5.91 \\
W/L & 0.53 & 0.08 & 0.53 & 0.48 & 0.58 & 0.15 & 1.00 \\
Perimeter $(\mu \mathrm{m})$ & 16.42 & 2.52 & 16.34 & 14.61 & 18.12 & 7.35 & 30.30 \\
Elongation & 1.45 & 0.22 & 1.42 & 1.29 & 1.57 & 1.03 & 3.30 \\
$\quad$ Pixelation & 138.7 & 20.4 & 137.7 & 123.86 & 153.71 & 41.8 & 214.5 \\
N/C area $(\%)$ & 13.34 & 4.01 & 12.89 & 10.40 & 15.80 & 3.05 & 31.58 \\
\hline
\end{tabular}

W/L, ratio of cell or nuclear width to length; N/C, percentage of the nucleus relative to cell area.

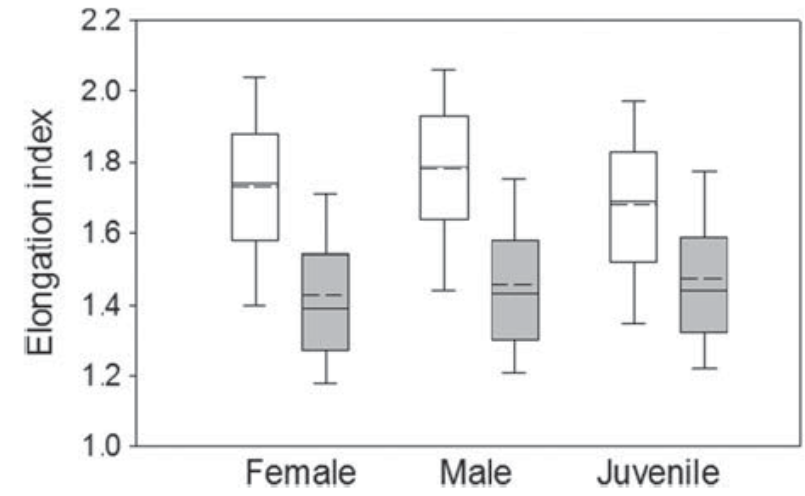

Fig. 2. Erythrocyte elongation index for cells (white) and nuclei (gray) of geometric tortoise cohorts. Box plots contain the median (solid line) and mean (broken line) and are bounded by $25^{\text {th }}$ and $75^{\text {th }}$ percentiles; error bars represent the $10^{\text {th }}$ and $90^{\text {th }}$ percentiles.

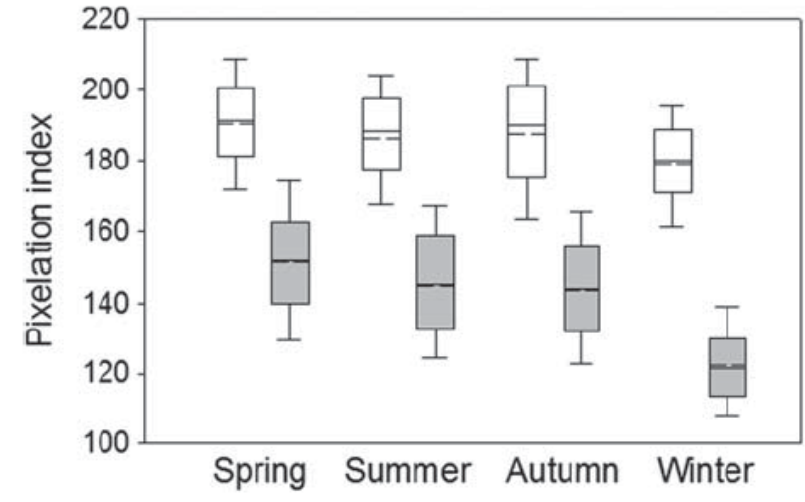

Fig. 3. Seasonal variation in the erythrocyte pixelation index for cells (white) and nuclei (gray) of geometric tortoises. Box plots contain the median (solid line) and mean (broken line) and are bounded by $25^{\text {th }}$ and $75^{\text {th }}$ percentiles; error bars represent the $10^{\text {th }}$ and $90^{\text {th }}$ percentiles.

The Nikon NIS automated imaging system demonstrated effectively size and shape differences among geometric tortoise cohorts. Males and juveniles had larger erythrocytes than females, a feature that can be attributed to erythrocyte length in males and erythrocyte width in juveniles. The wider erythrocytes of juveniles corresponded to results for erythrocyte shape, which was less elongated (rounder) in juveniles than in adults. 
Male and juvenile erythrocytes also had larger nuclei than females, which reflects results from the literature that in Testudinidae, nuclear size correlates with cell size (Ugurtas et al. 2003).

Female and male erythrocytes were more elongated than in juveniles. Elongation increases the surface area to volume ratio (Hartman and Lessler 1964), which indicates that gas exchange over erythrocyte surfaces would be more efficient in adult geometric tortoises than in juveniles. Because adults have larger bodies than juveniles, adults require more oxygen for their metabolic demands and the elongated erythrocytes would facilitate this. Female tortoises had elongated erythrocytes and their erythrocytes were the smallest of the cohorts, which enhances the uptake and release of oxygen over the erythrocyte surface. These advantages for gas transport in females likely are related to the fact that females are larger than males (Baard 1990) and may also reflect the high metabolic demand of egg production and nesting (Kuchling 1999).

Differences in N/C and pixelation intensity may be attributed to differences in erythropoietic activity among cohorts. The high $\mathrm{N} / \mathrm{C}$ ratios of males and juveniles may indicate that they had more circulating immature erythrocytes than females. Circulating blood of reptiles, particularly juveniles, always contains a percentage of immature erythrocytes (Pienaar 1962, Campbell 2004) and the progression from immaturity to maturity involves a reduction in nuclear size relative to cell size (Reavill 1994, Mader 2000, Zhang et al. 2011). This progression also results in a gradual change in staining proper- ties of the cytoplasm and nucleus from intensely to lightly basophilic (Knotkova et al. 2002). It is note- worthy that pixelation intensity showed that male and juvenile erythrocytes (cytoplasm and nuclei) stained more intensely than those of females.

There is no clear explanation why males and juveniles may have had more immature erythrocytes than females, but the supposition that pix- elation intensity reflects the ratio of immature to mature erythrocytes is supported by our seasonal evaluation of pixelation intensity. Geometric tortoises live in a Mediterranean climate, where they are relatively inactive during the dry summer and autumn months (Hofmeyr et al. 2012). Rainfall in late autumn to early winter stimulates plant growth and increases the food available for herbivores (Joshua et al. 2005) including geometric tortoises. It seems reasonable that one or more of these factors may stimulate erythropoiesis to prepare these ectotherms for greater oxygen demands in the spring when activity levels increase in response to abundant food supplies, elevated temperatures and reproductive activity (Hofmeyr et al. 2012). It is likely that the more intense staining of erythrocyte cytoplasm and nuclei among the winter cohort reflected increased numbers of mature erythrocytes in the circulation.

The Nikon NIS Elements imaging software provided a rapid and reliable method to determine cell and nuclear size and shape. In addition, pixelation intensity and the derived $\mathrm{N} / \mathrm{C}$ value appear to be useful indicators of erythropoietic activity, which may be due to either normal physiological cycles or disease conditions that may appear as

\section{http://repository.uwc.ac.za}


regenerative anemia. Automated measurements eliminated the cumbersome use of ocular measurements and manual calculations, which has been the standard practice for erythrocyte evaluation (Arikan and Cicek 2010). In addition, manipulation of visual features for the NIS Elements imaging software diminished the effects of staining artefacts or imperfections of the blood smear. Because the automated method produces rapid, accurate measurements of a variety of morphological characteristics of erythrocytes, it is particularly suitable for standardizing hematological measurements required for baseline studies and health assessment of wild or captive vertebrate populations. This information is crucial for conservation management of threatened species including the critically endangered geometric tortoise studied here. Furthermore, the automated method provides a rapid, objective and accurate way to evaluate evolutionary implications of inter-taxa differences in blood cell morphologies of vertebrates.

\section{Acknowledgments}

We are grateful to Elizabeth Parker and Mike Gregor for permission to work at Elandsberg Nature Reserve, and for the assistance of CapeNature staff with tortoise collection. The National Research Foundation and University of the Western Cape provided funds for this study.

Declaration of interest: The authors report no conflict of interest. The authors alone are responsible for the contents and writing of the paper. 


\section{References}

Aird B (2000) Clinical and hematological manifestations of anemia. In: Schalm's Veterinary Hematology, $5^{\text {th }}$ ed. Feldman BF, Zinkl JG, Jain NC, Eds., Lippincott Williams \& Wilkins, Baltimore. pp. 140-142.

Andrews CB, Mackenzie SA, Gregory TR (2008) Genome size and wing parameters in passerine birds. Proc. R. Soc. B 276: 55-61.

Arikan H, Cicek K (2010) Morphology of peripheral blood cells from various species of Turkish herpetofauna. Acta Herpetol. 5: 179-198.

Baard EHW (1990) Biological Aspects and Conservation Status of the Geometric Tortoise, Psammobates Geometricus (Linnaeus, 1758) (Cryptodira: Testudinidae). Ph.D. disserta- tion, University of Stellenbosch, South Africa.

Baard EHW, Hofmeyr MD (in press) Psammobates geome- tricus. In: Atlas and Red List of the Reptiles of South Africa, Lesotho and Swaziland. Bates MF, Branch WR, Bauer AM, Burger M, Marais J, Alexander GJ, de Villiers MS, Eds., SANBI, Cape Town.

Campbell TW (2004) Hematology of lower vertebrates. In: $55^{\text {th }}$ Annual Meeting of the American College of Veterinary Pathologists (ACVP) and $39^{\text {th }}$ Annual Meeting of the American Society of Clinical Pathology (ASVCP). American College of Veterinary Pathologists \& American Society for Veteri- nary Clinical Pathology, Middleton, WI. pp. 1214-1218.

Claver JA, Quaglia AIE (2009) Comparative morphology, development, and function of blood cells in nonmamma- lian vertebrates. J. Exot. Pet Med. 18: 87-97.

Dessauer HC (1970) Blood chemistry of reptiles: physi- ological and evolutionary aspects. In: Biology of the Reptilia, vol. 3, Gans C, Parsons TS, Eds., Academic Press, London. pp. 1-72.

Gregory TR (2001) The bigger the C-value, the larger the cell: genome size and red blood cell size in vertebrates. Blood Cells Mol. Dis. 27: 830-843.

Gregory TR, Andrews CV, McGuire JA, Witt CC (2009) The smallest avian genomes are found in hummingbirds. Proc. R. Soc. B 276: 3753-3757.

Harding JM, Torrez-Velez F, Latimer KS, Tarpley HL, LeRoy BE (2005) Sea turtle venipuncture and leukocyte morphology. Veterinary Clinical Pathology Clerkship Program. http://www.vet.uga.edu/vpp/clerk/harding/index.ph.

Hartman FA, Lessler MA (1964) Erythrocyte measurement in fishes, amphibia and reptiles. Biol. Bull. 126: 83-88.

Hofmeyr MD, van Bloemestein U, Henen B, Weatherby C (2012) Sexual and environmental variation in the space requirements of the critically endangered geometric tortoise, Psammobates geometricus. Amphib. Rept. 33: 185-197.

Houwen B (2000) Blood film preparation and staining procedures. Lab. Hematol. 6: 17.

Joshua QI, Hofmeyr MD, Henen BT, Weitz FM (2005) Seasonal changes in the vegetation of island and main- land habitats of angulate tortoises in the Western Cape, South Africa. S. Afr. J. Sci. 101: 439-445. 
Knotek Z, Knotková Z, Trnková S (2006) Advances in reptilian hematology and blood chemistry. Proceedings of the 31st World Small Animal Association Congress, 12th European Congress FECAVA, and 14th Czech Small Animal Veterinary Association CongressCzech Small Animal Veteri- nary Association, Prague. pp. 334-336.

Knotková Z, Doubek J, Knotek Z, Hájková P (2002) Blood cell morphology and plasma biochemistry in Russian tor- toises (Agrionemys horsfieldii). Acta Vet. Brno 71: 191198.

Kuchling G (1999) The Reproductive Biology of the Chelonia. Springer Publishers, Berlin.

Mader DR (2000) Normal hematology of reptiles. In: Schalm's Veterinary Hematology, $5^{\text {th }}$ ed. Feldman BF, Zinkl JG and Jain NC, Eds., Lippincott Williams \& Wilkins, Baltimore. pp. 1126-1132.

Morera D, MacKenzie SA (2011) Is there a direct role for erythrocytes in the immune response? Vet. Res. 42: 1-8. Pendl H (2006) Morphological changes in red blood cells of birds and reptiles and their interpretation. Isr. J. Vet. Med. 61: 1-12.

Pienaar U de V (1962) Haematology of Some South African Reptiles. Witwatersrand University Press, Johannesburg, South Africa.

Ponsen S, Talabmook C, Narkkong N, Aengwanich W (2008) Blood cell characteristics and some hematologi- cal values of sand lizards (Leiolepis belliana rubritaeniata Mertens 1961) in northeastern Thailand. Int. J. Zool. Res. 4: 119-123.

Reavill D (1994) Selected topics in reptile clinical pathol- ogy. Lecture given at the U.C.Davis Avian/Exotic Animal Symposium. http://www.zooexotic.com/Reptileclinpath 1994.pdf.

Saint Girons MC (1970) Morphology of the circulating blood cells. In: Biology of the Reptilia, Vol. 3. Morphology C, Gans C, Parsons TS, Eds., Academic Press, London. pp. 73-91.

Shadkhast M, Shabazkia H, Bigham-Sadegh A, Shariati SE, Mahmoudi T, Shariffian-Fard M (2010) The morphological characterization of the blood cells in the Central Asian tortoise (Testudo horsfieldii). Vet. Res. Forum 1: 134-141.

Snyder GK, Sheafor BA (1999) Red blood cells: centre- piece in the evolution of the vertebrate circulatory system. Am. Zool. 39: 189-198.

Solomon, H (1978) Crofton's theorem and Sylvester's problem in two and three dimensions. In: Geometric Prob- ability, Ch. 5, SIAM, Philadelphia, PA. pp. 97-125.

Strik NI, Alleman AR, Harr KE (2007) Circulating inflammatory cells. In: Infectious Diseases and Pathology of Reptiles. Jacobson ER, Ed., CRC Press, Taylor \& Francis Group, Boca Raton, FL. pp. 167-218.

Ugurtas IH, Sevine M, Yildirimhan HS (2003) Erythro- cyte size and morphology of some tortoises and turtles from Turkey. Zool. Stud. 42: 173-178.

Zhang F, Hexiang GU, Pipeng LI (2011) A review of chelonian hematology. Asian Herpetol. Res. 2: 12-20. 